\title{
Characterizing and mapping cropping patterns in a complex agro-ecosystem: An iterative participatory mapping procedure using machine learning algorithms and MODIS vegetation indices
}

\author{
Gudina Legese Feyisa ${ }^{\mathrm{a}, \mathrm{b}, *}$, Leo Kris Palao ${ }^{\mathrm{a}}$, Andy Nelson ${ }^{\mathrm{c}}$, Murali Krishna Gumma ${ }^{\mathrm{d}}$, \\ Ambica Paliwal $^{\mathrm{a}, \mathrm{e}}$, Khin Thawda Win ${ }^{\mathrm{f}}$, Khin Htar Nge ${ }^{g}$, David E. Johnson ${ }^{\mathrm{a}}$ \\ ${ }^{a}$ International Rice Research Institute (IRRI), Los Baños 4301, Laguna, Philippines \\ ${ }^{\mathrm{b}}$ Addis Ababa University, Centre for Environmental Science, P.O. Box 1176, Addis Ababa, Ethiopia \\ ${ }^{\mathrm{c}}$ Faculty of Geo-information Science and Earth Observation (ITC), University of Twente, Enschede 7500AE, the Netherlands \\ ${ }^{\mathrm{d}}$ Systems Analysis for Climate Smart Agriculture, Innovation Systems for the Drylands, International Crops Research Institute for the Semi-Arid Tropics, Patancheru, \\ Hyderabad, Telangana 502324, India \\ ${ }^{\mathrm{e}}$ University of Michigan, Ann Arbor, MI 48109, USA \\ ${ }^{\mathrm{f}}$ Graduate School of Agricultural and Life Sciences, The University of Tokyo, 1-1-1 Yayoi, Bunkyo-ku, Tokyo 113-8657, Japan \\ ${ }^{\mathrm{g}}$ IRRI Myanmar Office, Department of Agriculture, Gyogone, Insein Road, Yangon, Myanmar
}

\section{A R T I C L E IN F O}

\section{Keywords:}

Classification accuracy

MODIS

Time-series

Participatory mapping, machine learning

\begin{abstract}
A B S T R A C T
Accurate and up-to-date spatial agricultural information is essential for applications including agro-environmental assessment, crop management, and appropriate targeting of agricultural technologies. There is growing research interest in spatial analysis of agricultural ecosystems applying satellite remote sensing technologies. However, usability of information generated from many of remotely sensed data is often constrained by accuracy problems. This is of particular concern in mapping complex agro-ecosystems in countries where small farm holdings are dominated by diverse crop types. This study is a contribution to the ongoing efforts towards overcoming accuracy challenges faced in remote sensing of agricultural ecosystems. We applied time-series analysis of vegetation indices (Normalized Difference Vegetation Index (NDVI) and Enhanced Vegetation Index (EVI)) derived from the Moderate Resolution Imaging Spectrometer (MODIS) sensor to detect seasonal patterns of irrigated and rainfed cropping patterns in five townships in the Central Dry Zone of Myanmar, which is an important agricultural region of the country has been poorly mapped with respect to cropping practices. To improve mapping accuracy and map legend completeness, we implemented a combination of (i) an iterative participatory approach to field data collection and classification, (ii) the identification of appropriate size and types of predictor variables (VIs), and (iii) evaluation of the suitability of three Machine Learning algorithms: Support Vector Machine (SVM), Random Forest (RF), and C5.0 algorithms under varying training sample sizes. Through these procedures, we were able to progressively improve accuracy and achieve maximum overall accuracy of $95 \%$ When a small sized training dataset was used, accuracy achieved by RF was significantly higher compared to SVM and C5.0 $(\mathrm{P}<0.01)$, but as sample size increased, accuracy differences among the three machine learning algorithms diminished. Accuracy achieved by use of NDVI was consistently better than that of EVI $(\mathrm{P}<0.01)$. The maximum overall accuracy was achieved using RF and 8-days NDVI composites for three years of remote sensing data. In conclusion, our findings highlight the important role of participatory classification, especially in areas where cropping systems are highly diverse and differ over space and time. We also show that the choice of classifiers and size of predictor variables are essential and complementary to the participatory mapping approach in achieving desired accuracy of cropping pattern mapping in areas where other sources of spatial information are scarce.
\end{abstract}

\footnotetext{
* Corresponding author at: Addis Ababa University, Centre for Environmental Science, P.O. Box 1176, Addis Ababa, Ethiopia.

E-mail address: fgudina@gmail.com (G.L. Feyisa).
} 


\section{Introduction}

Accurate and up-to-date space-time information on crop production is essential for agricultural decision making and planning processes to support food security efforts in low income countries. This is particularly important in countries such as Myanmar where reliable agricultural databases are in short supply (Haggblade and Boughton, 2013). Decades of economic and political isolation of Myanmar and low investment in agricultural research have hindered exchange of technology and know-how, contributing to Myanmar's recent high rates of hunger and malnutrition (Haggblade and Boughton, 2013).

In the Central Dry Zone (CDZ) of Myanmar, increased cropping intensity is seen as one of the major opportunities to increase production given the lack of available land for expansion, and the slow rate of growth in yield of existing crops. Accurately mapping the existing cropping intensity so as to identify areas where intensity can be further sustainably increased is thus an important contribution to more sustainable use of natural resource. The cropping patterns in the CDZ are highly variable and governed by a number of environmental drivers (SeinnSeinn et al., 2015; Yee and Nawata, 2014), government policies and socioeconomic factors (Boughton et al., 2015; Tun et al., 2015; Yee and Nawata, 2014). These factors interact in space and time resulting in many possible seasonal patterns of cereal, vegetable, tuber and pulse production. In such sequential cropping systems, the cropping intensity (the number of sequential crops harvested per year on the same plot of land) can be as high as three or four in intensively managed systems. Double cropping is a predominant system, which is a typical characteristic across many parts of Asia where cropping intensity is higher than any other region of the world (Gray et al., 2014; Siebert et al., 2010). Small holder agriculture in Southeast Asia in general and Myanmar in particular is also characterized by small and fragmented landholdings coupled with spatially diverse combinations of cropping patterns.

Mapping the spatial and temporal dynamics of cropping patterns and characterizing agroecosystems with acceptable levels of accuracy is important information for meaningful cost effective upscaling of agricultural technology interventions. Remote sensing is an important source of data to provide an overview of croplands due to its capability to detect and monitor the spatiotemporal dynamics of crop, soil and water conditions, with applications ranging from field to global levels (Atzberger, 2013). At national or sub-national scales, satellite data, such as imagery from MODIS, Landsat, Satellite Pour l'Observation de la Terre (SPOT), and Sentinel have become important sources of multispectral and multitemporal information for identifying crop types and crop management practices (Foerster et al., 2012; Long et al., 2013; Maponya et al., 2020; Rajeswari and Suthendran, 2019; Tatsumi et al., 2015; Wardlow et al., 2007; Zhong, 2012). The basis for remote sensing-based cropping patterns information is the unique temporal patterns of crop phenology which can be characterized through analysis of the multi-temporal signature of vegetation indices (VIs) such as the Normalized Difference Vegetation Index (NDVI) and Enhanced Vegetation Index (EVI) (Hmimina et al., 2013; Long et al., 2013; Sakamoto et al., 2014; Zhong, 2012). MODIS data provides a unique opportunity to detect seasonal patterns of crop phenology due to its high temporal resolution, and has been successfully applied to generate valuable spatial crop information (Araya et al., 2016; Gumma et al., 2014; Peng et al., 2014; Seo et al., 2019; Wardlow et al., 2007).

However, in environments where cropping systems are dominated by fragmented landscapes with spatial and temporal diversity in cropping patterns, which is typical of agroecosystems in the CDZ, the use of remotely sensed satellite data such as those from Moderate Resolution Imaging Spectroradiometer (MODIS) often results in levels of accuracies that are lower than desired.

Understanding relationships between spatial resolution and classification accuracy has long been interesting research area (Duveiller and Defourny, 2010; Waldner and Defourny, 2017). The spatial resolution of an instrument is related to its capability to resolve high spatial frequencies, which mainly depend the ground sampling distance, the modulation transfer function and the signal-to-noise ratio (Duveiller and Defourny, 2010). A study by Markham and Townshend (1981) concluded that classification accuracy reflects a trade-off between the within-class variability and the boundary effect. Chen et al. (2016) conducted a study to understand effects of spatial heterogeneity on crop area mapping using MODIS data and found out that classification accuracy of MODIS imagery is sensitive to both sample impurity and landscape heterogeneity.

Several methods have been devised to mitigate inaccuracies related to the coarse resolution of MODIS; these include approaches to improve spatial resolution through the fusion of data from different sensors (Chen et al., 2014; Gumma et al., 2011), and techniques for combining various classification algorithms such as the combined use of objectbased and pixel-based classification (Rodriguez-Galiano et al., 2012; Shao and Lunetta, 2012). A large number of comparative studies has also attempted to identify the relative suitability of different classification methods. Studies such as Qian et al. (2014), Liu et al. (2013), Shao and Lunetta (2012) and Fernández-Delgado et al. (2014) have generally indicated that machine learning algorithms (mainly Random Forest (RF) and Support Vector Machine (SVM)) are superior in achieving high classification accuracies. However, the conclusions from many of such comparative studies are often inconsistent (FernándezDelgado et al., 2014; Li et al., 2014). The suitability of different classification algorithms depended on several factors including sizes and purity of the training sample (Li et al., 2014; Shao and Lunetta, 2012), class imbalance (Waldner et al., 2019), parameter tuning (Li et al., 2014; Sonobe et al., 2014),selection of training and auxiliary data (Zhu et al., 2016)whether the classification is pixel-based or object-based (Duro et al., 2012; Qian et al., 2014; Sonobe et al., 2014), and performance criteria used in assessing the accuracy of the classifiers (Caruana and Niculescu-Mizil, 2006).

The present study is a contribution to ongoing efforts to identify and develop a classification approach which significantly improves classification accuracies in complex agricultural environments. The specific objectives in this study were, therefore, 1) to investigate whether knowledge of land users and agricultural experts can be used to improve accuracy cropping pattern mapping, and 2) to identify locally suitable classification approaches for accurate characterization of cropping patterns and crop ecosystems in data-scarce complex agricultural environment of Central Dry Zone of Myanmar. The information developed in this study is an attempt to fill spatial information gaps and facilitate efficient targeting of agricultural productivity enhancing technologies, and improving access to crop production information in Myanmar. We integrated time-series analysis of MODIS VIs with detailed knowledge possessed by local farmers and agricultural officers in our approach. Local knowledge can provide an overview of the agricultural landscape, indicating predominant cropping patterns that occur in one area as distinct from another while, at the same time, describing crops and practices at particular locations and how this might change over time and space. In this study, we applied this participatory mapping procedures and evaluated the classification performance of three state-of-the-art machine learning algorithms (RF, SVM and C5.0) using 8-day, 16-day and monthly composites of MODIS VI products.

\section{Description of the study area}

The CDZ covers 55,000 $\mathrm{km}^{2}$ and comprises the Magway, Mandalay and lower Sagaing regions. The study was undertaken in five townships of the CDZ: Ye'u, Monywa, Pakokku, Wundwin and Pyawbe. The study sites lie between $20^{\circ} 23^{\prime} 24^{\prime \prime} \mathrm{N}$ to $23^{\circ} 2^{\prime} 24^{\prime \prime}$ latitude and $94^{\circ} 40^{\prime} 12^{\prime \prime} \mathrm{E}$ to $96^{\circ} 20^{\prime} 24^{\prime \prime} \mathrm{E}$ longitude (Fig. 1). The area is transected north to south by the Chindwin and Ayeyarwady rivers, and the topography is gently undulating at about $300 \mathrm{~m}$ above sea level with altitude ranging 


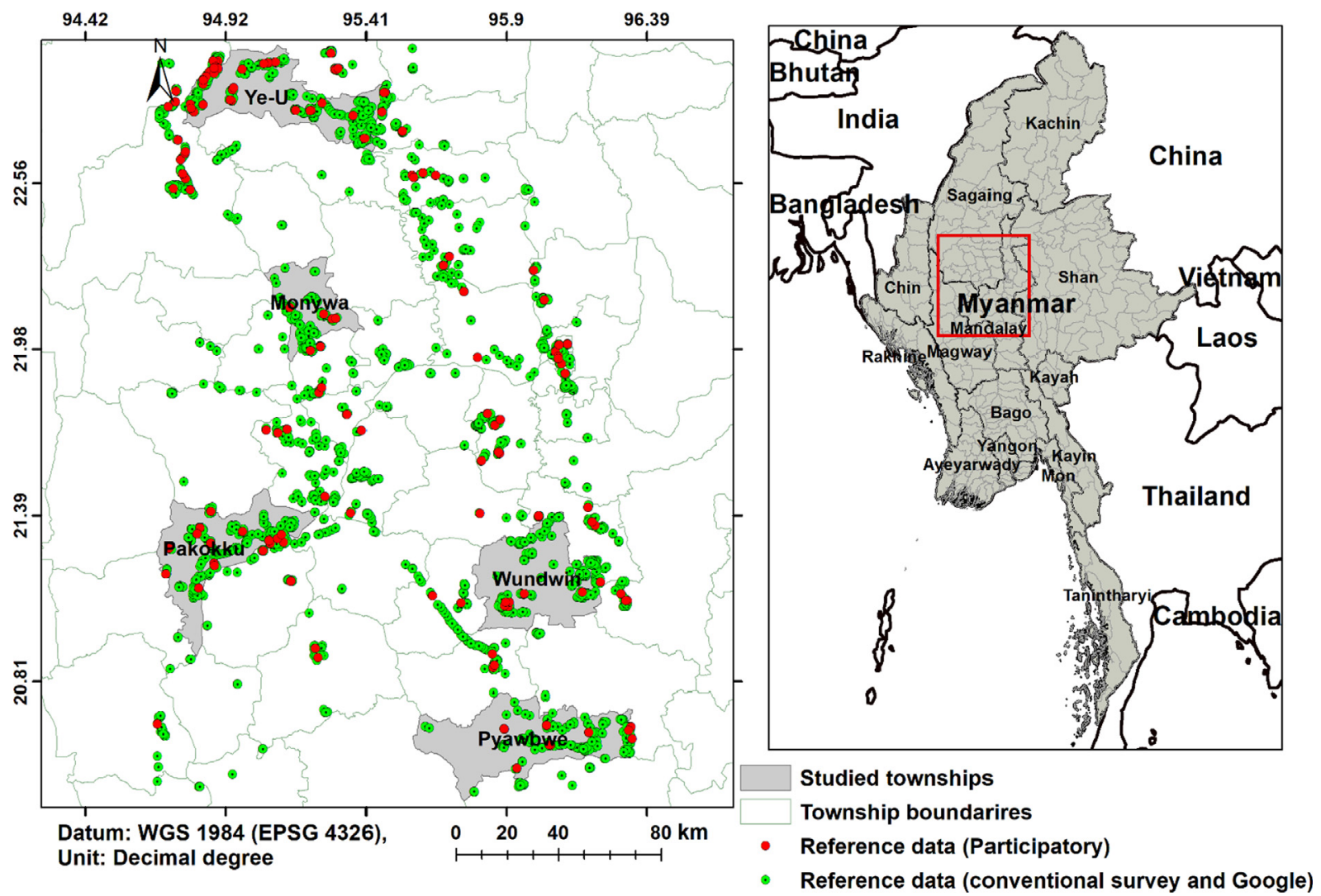

Fig. 1. Map of study area and locations of sample points.

between 62 and $658 \mathrm{~m}$ above sea level. The climate of the study area is characterized by low rainfall, with an average annual rainfall of $833 \mathrm{~mm}$ across townships. The monsoon season is divided into two: the pre-monsoon season, which starts in May, and the major monsoon season, which starts in August and ends in October. Most streams are dry for much of the year. Average minimum and maximum temperatures are $21{ }^{\circ} \mathrm{C}$ and $31.9{ }^{\circ} \mathrm{C}$, respectively (source: local agro-meteorological stations of each Township).

The CDZ tends to be resource poor; water is scarce and crop losses to drought are frequent and vegetation cover is thin and there is severe soil erosion. In some areas, in addition to drought, soil salinity is a constraint. There is a dearth of detailed current information on the cropping systems and agricultural potential of the CDZ. This presents a major challenge to the development of technologies which are likely to be well adapted to such locations (e.g. upland or alkaline soil conditions) and certain cropping systems (e.g. short duration rice varieties for the rainfed monsoon crop to be followed by legume crops cultivated with the residual soil moisture). Detailed spatial information on current cropping patterns is essential for adaptive research and targeting of improved options for farmers.

The CDZ is characterized by small holder crop production systems. In many places of the studied townships, irrigation facilities offer the possibility of producing a number of crops throughout the year. Double and even triple cropping systems are common in many villages of the studied areas, which could benefit from full irrigation or supplemental irrigation. In the rainfed upland areas, two crops per year may be grown, comprising sunflower (Helianthus annuus), sesame (Sesamum indicum), groundnut (Arachis hypogaea), green gram (Vigna radiata), maize (Zea mais) or butter bean (Phaseolus lunatus) or a single crop of pigeon pea (Cajanus cajan), cotton (Gossypium sp.) or sugar cane (Saccharum officinarum). In the lowland rainfed areas, monsoon rice (Oryza sativa) may be followed by either chickpea (Cicer arietinum), green gram or other pulses. In irrigated areas, two crops of rice may be grown as well as a crop of chickpea, sunflower or others (the majority are pulses). Double cropping is also made possible due to local topography and rainfall resulting in sufficient soil moisture to support low water use crops such as sorghum (Sorghum bicolor), groundnuts and chickpea. Areas that produce a single crop per year are also common; especially during years of low rainfall or late onset of rainfall.

\section{Methods}

\subsection{Data types and sources}

Three years of VI data (2012-14) derived from MODIS Terra and Aqua satellites (NDVI and EVI) in 8-day, 16-day and monthly composites were acquired from the USGS data portal http://earthexplorer. usgs.gov (USGS, 2015). We collected reference and validation data from four sources. (1) Ground-based characterization of land cover types, including information such as current crop cover types, cropping calendars for each crop, water source for crop production were collected through field surveys, which were conducted in March 2013, August 2014 and November 2015. (2) Information about historical cropping patterns was collected through discussions with local farmers (November 2015) and we identified 10 major cropping patterns and 4 non-agricultural land cover types (Table 1). (3) High spatial resolution data from Google Maps ${ }^{\circledast}$ were also used to collect data on easy-toidentify, non-cropland land use/cover (LULC) types such as water bodies, forests and settlement areas. In total, we collected 3654 reference points from field and Google Earth. The spectral separability of reference data was assessed through the Transformed Divergence Separability Index (TDSI) in ENVI v5.2 (Exelis Visual Information Solutions, 2015). This index was useful in identifying classes that were not separable, and therefore merged into one. For instance, class 14 in Table 1 was named as 'Barren lands and other non-agricultural lands' because land covers that were non-agricultural lands and do not belong 
Table 1

Description of major cropping patterns and non-agricultural land use/cover types.

\begin{tabular}{|c|c|c|}
\hline No. & LULC/cropping pattern & Descriptions \\
\hline 1 & Irrigated double rice & Irrigated rice in the monsoon, followed by rice in winter, fallow in summer \\
\hline 2 & Irrigated rice-upland crops & Irrigated rice in the monsoon, followed by upland crops in winter \\
\hline 3 & Irrigated double upland crops & Irrigated non-rice crops in monsoon and winter \\
\hline 4 & $\begin{array}{l}\text { Irrigated rice followed by two upland } \\
\text { crops }\end{array}$ & Irrigated rice in the monsoon, followed by upland crops in winter and summer \\
\hline 5 & Recession crops & $\begin{array}{l}\text { A cropping pattern found near rivers and lakes, where water covers the crop land during the monsoon and in the dry season } \\
\text { different crops are produced using residual moisture as the water recedes }\end{array}$ \\
\hline 6 & Mixed crop class & Crop lands that are characterized by heterogeneous cropping patterns less than the MODIS pixel size \\
\hline 7 & Rainfed rice - upland crops & Rainfed rice during monsoon, followed by non-rice crops during winter/summer \\
\hline 8 & Rainfed double upland crops & Rainfed non-rice crops during monsoon and winter/summer \\
\hline 9 & Rainfed single rice & Rainfed rice during the monsoon and fallow during winter and summer \\
\hline 10 & Rainfed single upland crops & Rainfed non-rice crops during the monsoon and fallow during winter and summer \\
\hline 11 & Urban/settlements & Towns and cities, also villages where built-up surfaces predominate \\
\hline 12 & Water bodies & Large rivers and lakes \\
\hline 13 & Forest/woodlands & Forest reserves, plantation forests, woodlands dominated by scattered trees and grasslands, with no crop production \\
\hline 14 & $\begin{array}{l}\text { Barren lands and other non-agricultural } \\
\text { lands }\end{array}$ & Dry river beds, exposed rocky surfaces, with no/low vegetation cover \\
\hline
\end{tabular}

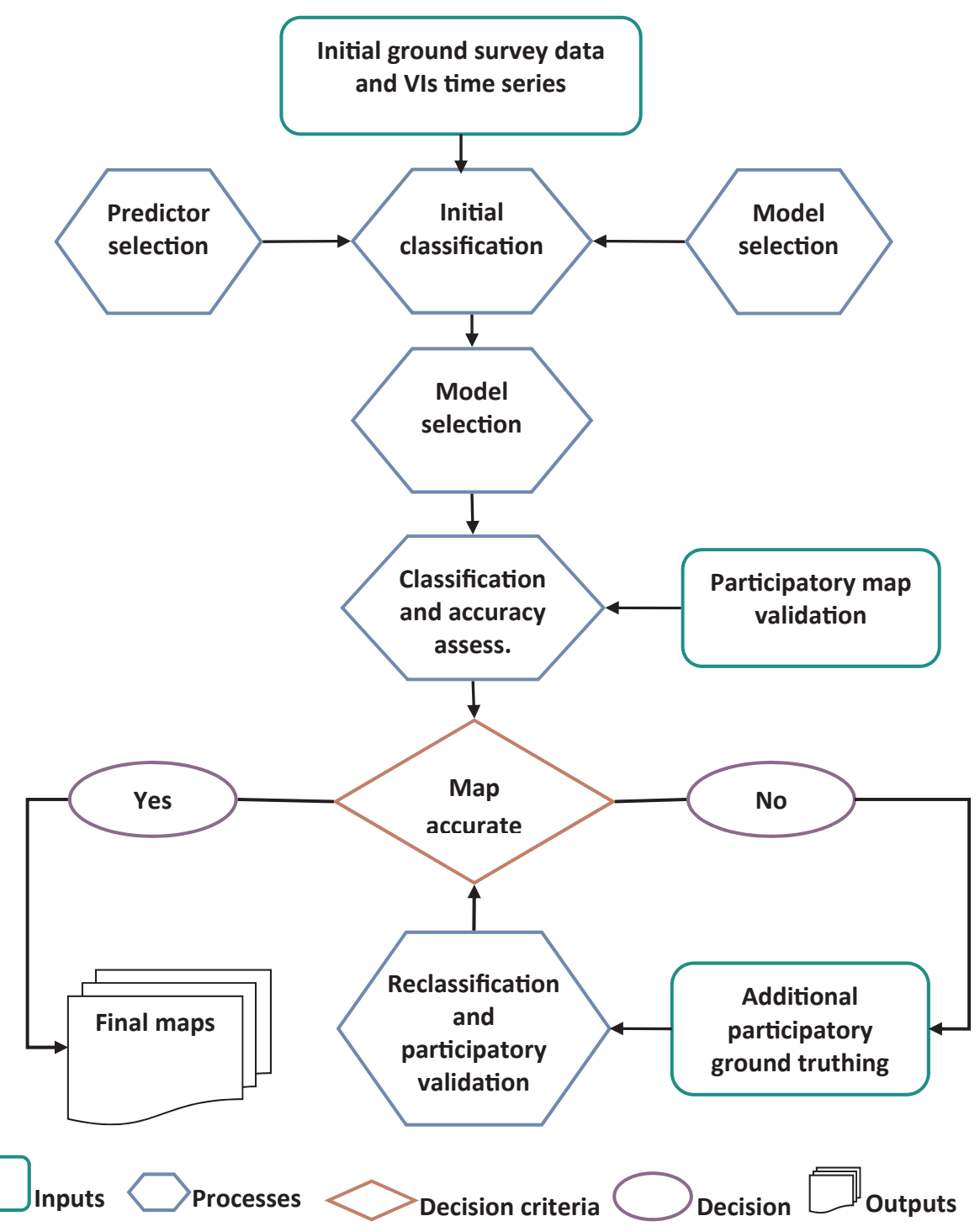

Fig. 2. Flow chart of analysis procedures. 
to any of the other listed classes were found to be inseparable when the TDSI was applied. (4) We obtained village-level estimates of area coverage of major crop types from government agricultural statistics.

\subsection{Model tuning, classification procedures and accuracy assessments}

We used three state-of-the-art machine learning supervised classification algorithms: support vector machine (SVM), Random Forest (RF) and C5.0 (a decision trees and rule-based model) and evaluated the suitability of these classifiers using varying sizes of training data. The performance of these algorithms was also evaluated using different temporal resolution of predictor variables (NDVI and EVI); that is, 8day, 16-day and monthly composites of the two vegetation indices (VIs) were used to compare accuracy differences among the classifiers. The underlying theory and detailed mathematical explanation of the machine learning algorithms have been documented in the literature (BenHur and Weston, 2010; Lek and Guégan, 2012; Michie et al., 1994; Pal, 2005; Pal and Mather, 2005).

Model building, parameter tuning, classification and accuracy assessment were performed using the 'caret' R-package and 'train' function of the 'caret' package (Kuhn et al., 2015), implemented in R language and statistical software v.3.1.2 (R Core Team, 2014). In addition to the 'caret' package, a number of other packages were used for image processing and geospatial analysis: the 'raster' package (Hijmans, 2015), 'rgdal' (Bivand et al., 2014), 'lattice' (Sarkar, 2008) and 'ggplot2' (Wickham, 2009). The 'optimal' tuning parameters of the three models compared in this study (SVM, RF and C5.0) were automatically determined by implementing a random search. Random 3 -fold cross validation repeated six times was applied, and a tune length of 5 was used. For the $R F$ model, the number of trees per node was set to 500 . In order to evaluate and compare performance of the three models, the predicted classes were compared against the "hold-out" test data.

User's and producer's accuracies, and overall accuracy were used as measures of accuracies, which are most widely used measures of assessing accuracy of thematic maps (Congalton and Green, 2008). A paired $t$-test was used to assess statistical significances of differences among accuracies (Foody, 2004). The test was implemented using 'caret' (Kuhn et al., 2015), which is based on Hothorn et al. (2005) and Eugster et al. (2008). In addition to these conventional accuracy assessments, we used a participatory and iterative map validation and reclassification procedures (see section 3.3) in order to overcome accuracy problems associated with high spatial details arising from heterogeneity of cropping patterns and small plot sizes in CDZ. Agricultural officers and township managers who have great detail of local knowledge of agricultural practices in the study area were involved in the iterative participatory mapping process. The participatory mapping was iterated at least three times at each of the five townships included in this study. A summary of classification procedures and accuracy assessment is shown in Fig. 2.

\subsection{Participatory iterative mapping process}

Mapping cropping patterns require knowledge about the dynamics of land cover over several seasons in a year. This may involve repeatedly monitoring the crop cover changes at same location and in different seasons. The main aim of the study was to investigate whether knowledge of land users and agricultural experts can efficiently be used in mapping cropping patterns. In areas where agricultural landscape is heterogeneous, collecting data about how many crops are grown in different seasons (single crop, double crop and triple crop, etc) and categories of different crops that grow at a given location in different seasons is not easy task. If one has to apply simple field observation, one would find only the crops that covers that location at the time of the field survey. Therefore, one has to visit the same location at multiple seasons of different years. To overcome this problem and produce usable agricultural information, we planned to incorporate local knowledge, which is often undermined in conventional mapping procedures.

The participants of the participatory mapping procedure were farmers and local agricultural experts, who are very much familiar with cropping systems in their townships. Cartographic literacy of was high amongst the agricultural experts because they are used to using topographic maps. The incentive for farmers for participating in the participatory mapping was that the township would be provided with more accurate maps and associated recommendations for improved cropping patterns and practices. This mapping procedure is a co-development process where both producers and users are involved in the map generation process.

At the initial stage, we collected reference data at random, both using ground-based survey and Google imagery, and without involving local community in the process. At this stage, we produced a preliminary map using 62 samples and implementing the classification procedure described under section 3.3. The first participatory mapping workshop was then held and the preliminary map was evaluated by group of farmers and Township-level agricultural experts. During the first workshop, areas with classification errors were marked by the participants; and the mapping team travelled to those areas and have taken samples at random locations, and the team collected 119 more samples targeting areas (on the preliminary map) where the workshop participants indicated misclassifications. The initial labels proposed in the preliminary map were improved and refined during the first participatory mapping workshop. The second mapping was undertaken using the total sample points of 476 . In addition to field surveys conducted to collect more data by focusing on the areas that participants marked as 'misclassification', we also used high spatial resolution imagery from Google Earth $^{\circledR}$ to collect more sample points, being guided by comments of the workshop participants. In so doing, we efficiently included more data and collected total of 1,868 samples and using these samples, we produced the third version of the map, which was then used in the third participatory mapping workshop. Based on feedback from the final workshop, we again collected more data from areas where misclassifications were identified in the participatory workshop. Finally, a total of 3,654 reference data points were collected with more attention being placed on areas where workshop participants had identified classification errors (Fig. 1).

\section{Results}

\subsection{Spectral profiles and separability analysis of reference data}

Fig. 3 shows profiles of NDVI and EVI for various land cover types for years 2012-14 and across different seasons of the years. The figure shows that rice-based cropping systems have low separability due to high similarity in patterns of VI signature. The lowest separability values were observed between rainfed double upland crops and irrigated double upland crops. Compared to EVI, NDVI shows better separability among non-agricultural LULC types such as bare land and urban/settlements. It was particularly clear that one year of monthly composite data of VI (NDVI and EVI) was not adequate to show spectral separability among classes, and that the highest separability was achieved from the 3-year time-series of 8-days VI composites data. For simplicity of visual interpretation, only, the VI temporal signature of 16-day composite is shown in Fig. 3.

\subsection{Accuracy improvements through participatory iterative mapping and model comparisons}

Fig. 4 shows the iterative accuracy improvement trends and accuracy variation among SVM, RF and C5.0 classifiers in response to increasing sample size. Results of day 1 in Fig. 4 shows low classification accuracy associated with the conventionally collected field data based on small sample size (total of 62 points). With small reference sample 

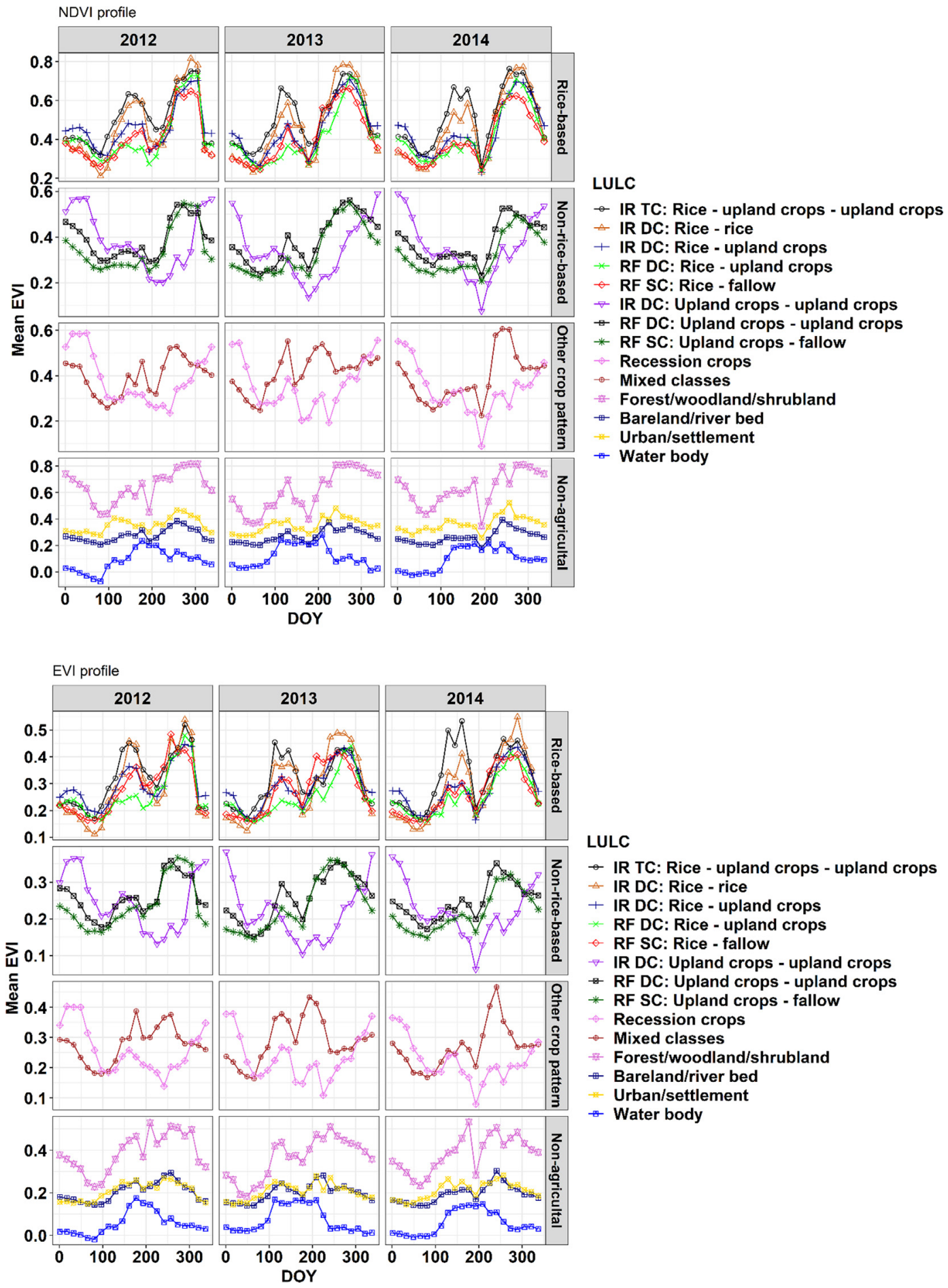

LULC

$\rightarrow$ IR TC: Rice - upland crops - upland crops

$\triangle$ IR DC: Rice - rice

+ IR DC: Rice - upland crops

* RF DC: Rice - upland crops

$\diamond$ RF SC: Rice - fallow

$\nabla$ IR DC: Upland crops - upland crops

* RF DC: Upland crops - upland crops

* RF SC: Upland crops - fallow

- Recession crops

- Mixed classes

* Forest/woodland/shrubland

\# Bareland/river bed

- Urban/settlement

- Water body

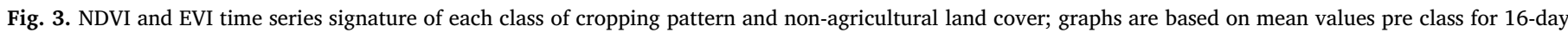
composites of VI data.

size, RF resulted in significantly higher accuracy compared to both SVM and C5.0 classifiers $(P<0.01)$ (Figs. 4 and 5). During the last few days of the mapping processes, substantial accuracy improvement was achieved and beyond sample size of about 2000 points, accuracy tended to saturate again. The accuracy difference between the initial classification and the final classification based on participatory reference data collection and iterative classification, is about $31 \%, 32 \%$ and $43 \%$ for the RF, SVM and C5.0 classifiers, respectively (Fig. 4).

As sample size increased, SVM tended to consistently outperform in most cases, and the C5.0 model resulted in the lowest accuracy (Fig. 4).
The accuracy difference among the classifiers tended to diminish as the size of training data set became larger (Fig. 5). When the final 3654 sample points were used, the accuracy of RF was shown to be slightly higher (95\%) than that of SVM (94\%).

\subsection{Comparison of VIs}

Accuracy also varied depending on whether NDVI or EVI was used in the classification, whether 8-day 16-day or monthly composite data was used and whether one or three years of data were used. The lowest 


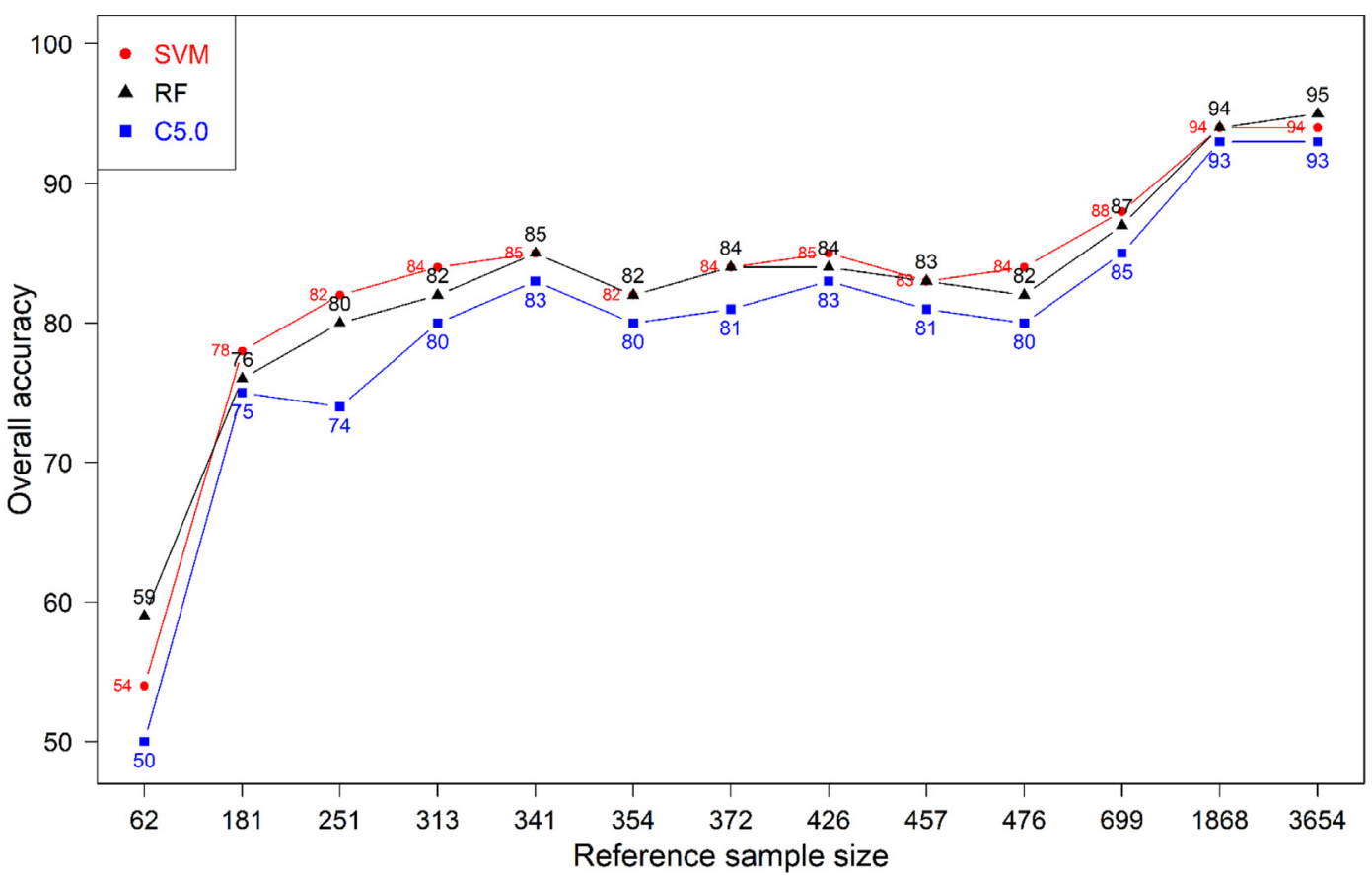

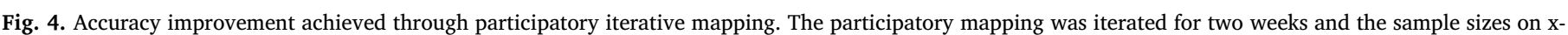

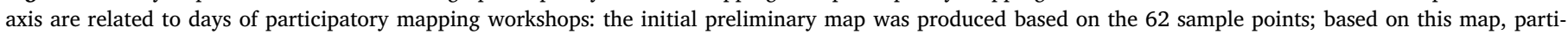

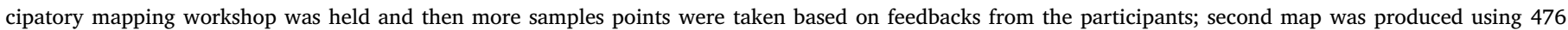

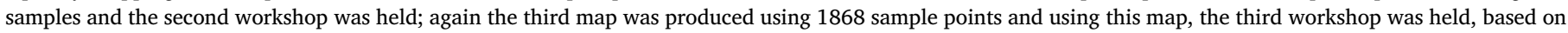

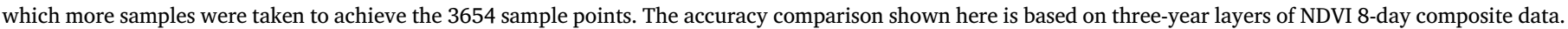

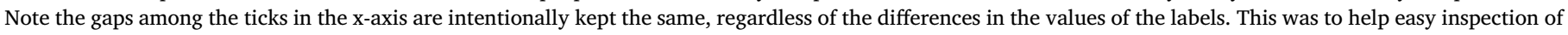
the changes in accuracy brought about by each progressive addition of more samples.

accuracy was observed when monthly EVI layers of one year (2014) were used (data not shown) and increasing the number of VIs layers (predictor variables) has considerably improved accuracy (Fig. 6). NDVI showed consistently higher accuracy than EVI, across monthly, 16-days and 8-day composites of three-year data layers. The accuracy differences between NDVI and EVI were highest at monthly composite of the VI, and the accuracy difference tended to become narrower as the number VI layers increases (Fig. 6).

The final maps of cropping pattern and land cover were developed using the SVM classifier with 8-day composite data of NDVI for three years (2012-14). Fig. 7 shows the final classification result for the five townships. Overall classification was 95.3\%2. Both user's and

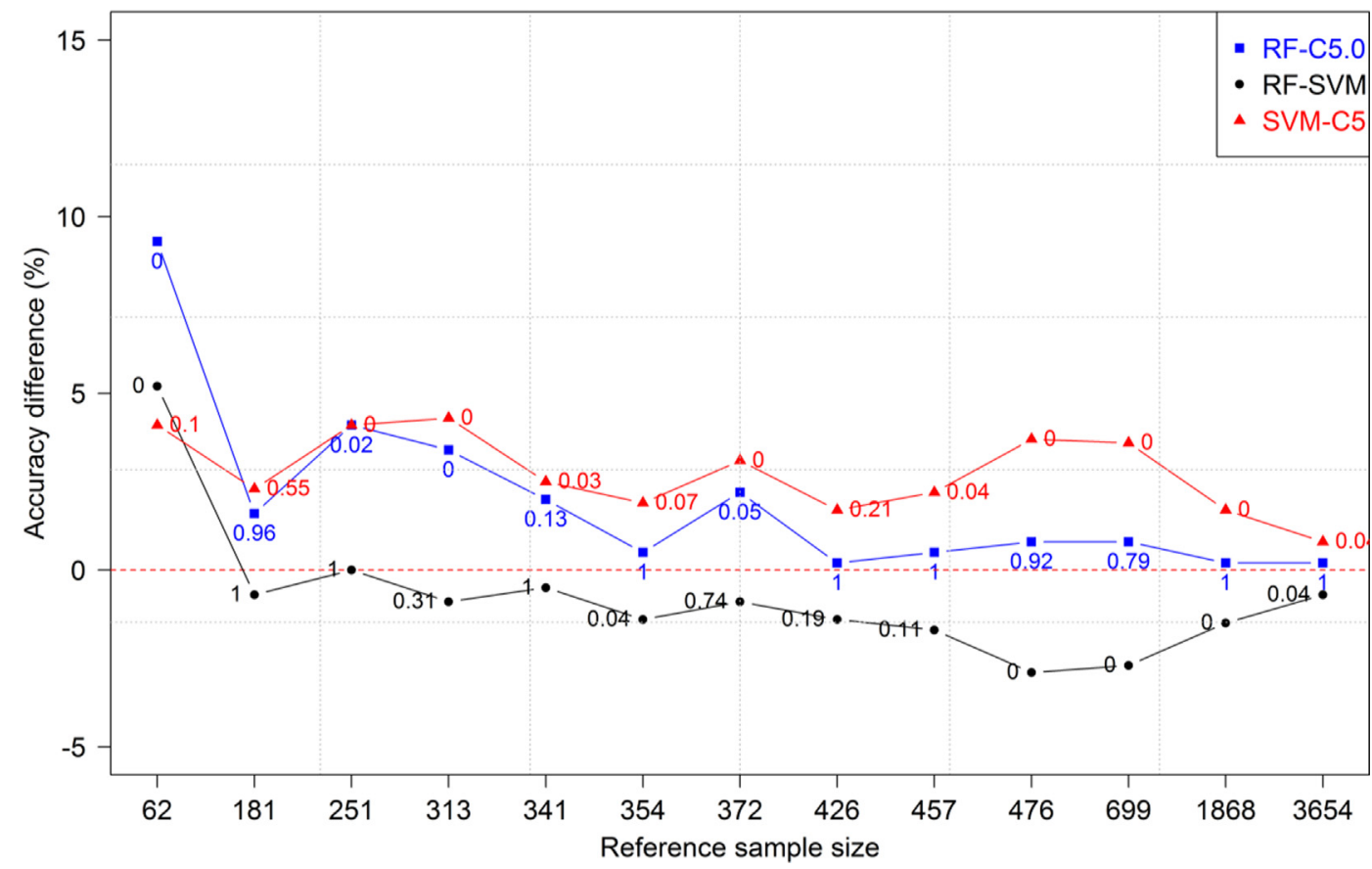

Fig. 5. Accuracy differences among the models with increasing size of reference data and 3-year stack of NDVI 8-day composite. The labels on the line graphs show pvalues. 


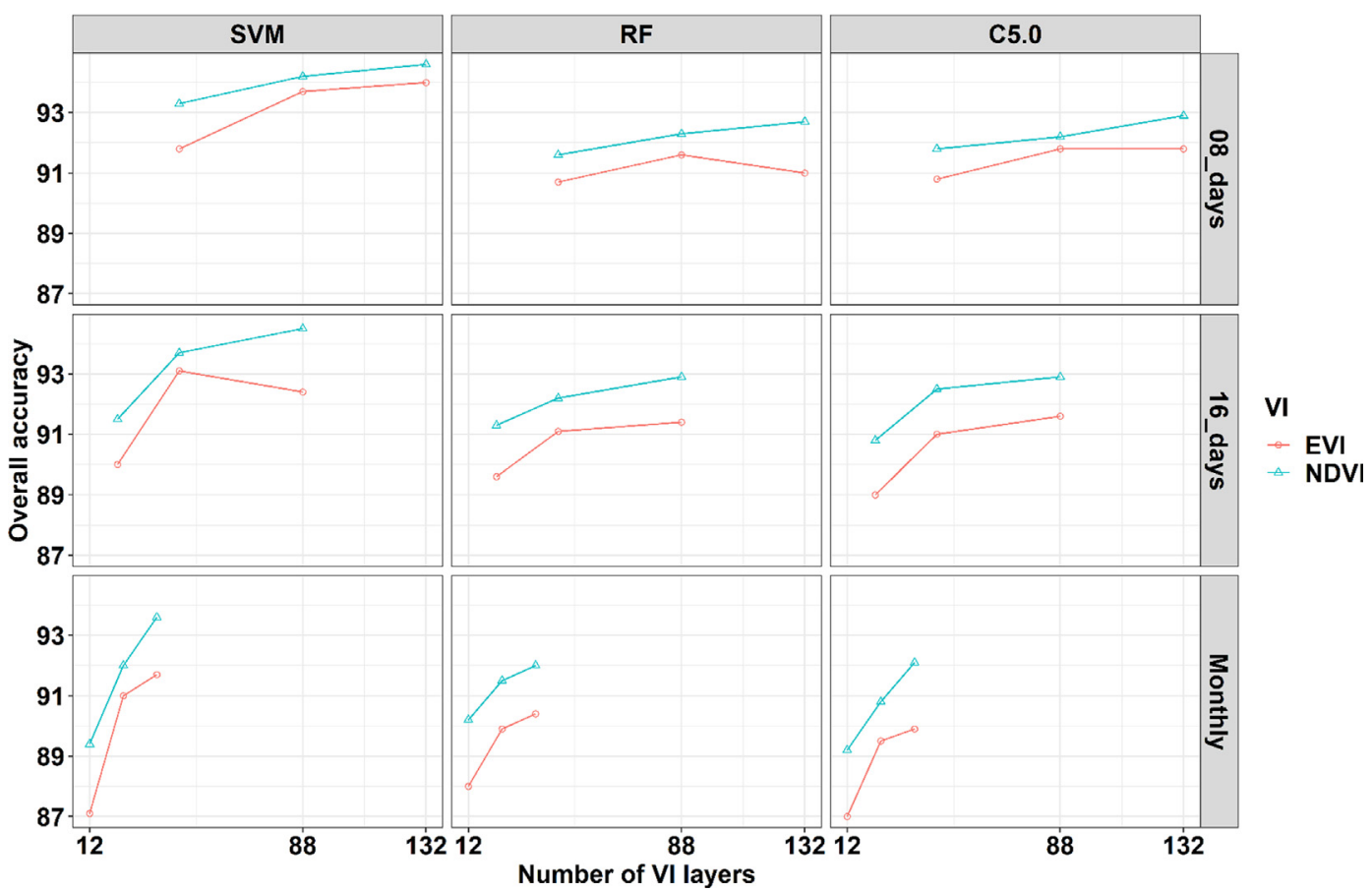

Fig. 6. Comparison of accuracy differences with three-year layers of monthly, 16-day and 8-day composites of NDVI and EVI.

producer's accuracy of all classes exceeded 74\% (Table 2). The smallest producer's and user's accuracies were due to large confusion among 'rainfed monsoon rice and winter/summer upland crops', 'irrigated monsoon rice and winter/summer upland crops', and 'rainfed monsoon upland crop and winter/summer upland crops' (Table 2).

\section{Discussion}

In this study we were able to substantially improve land cover and crop pattern mapping accuracies through participatory iterative mapping procedures and sequential identification of suitable dataset and classifier algorithm. Information regarding cropping patterns may not be easy to collect through conventional field survey, since at the time of field visits, one can see only one type of crop cover at a time unless a series of seasonal revisits at the same location are undertaken, which makes the such surveys highly time consuming and expensive. To counter this, information on local agricultural practices and the spatiotemporal dynamics of cropping systems were obtained through our
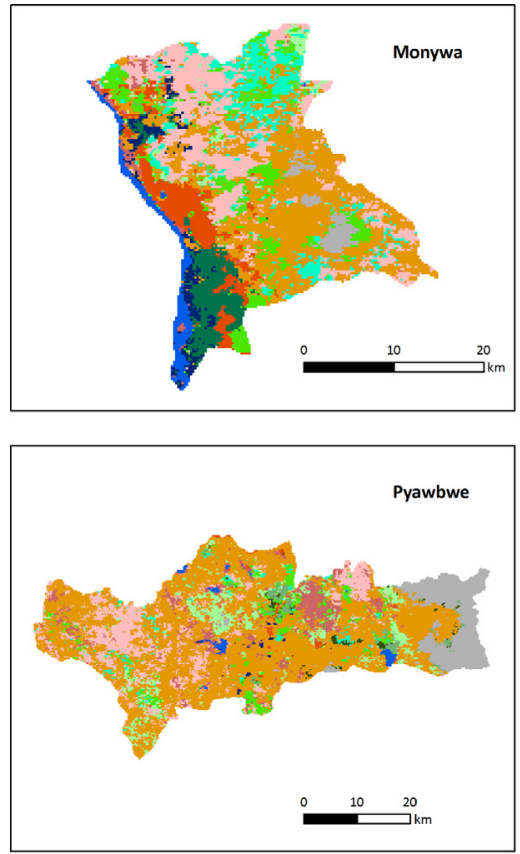

Notes:

IR - Irrigated, RF - Rainfed, TC - Triple Crop, DC - Double Crop, SC - Single Crop; dash line ( - ) indicated succeding crops planted Data source: MODIS MOD13Q1 (250 m resolution) 16 days composite from 2012-2014
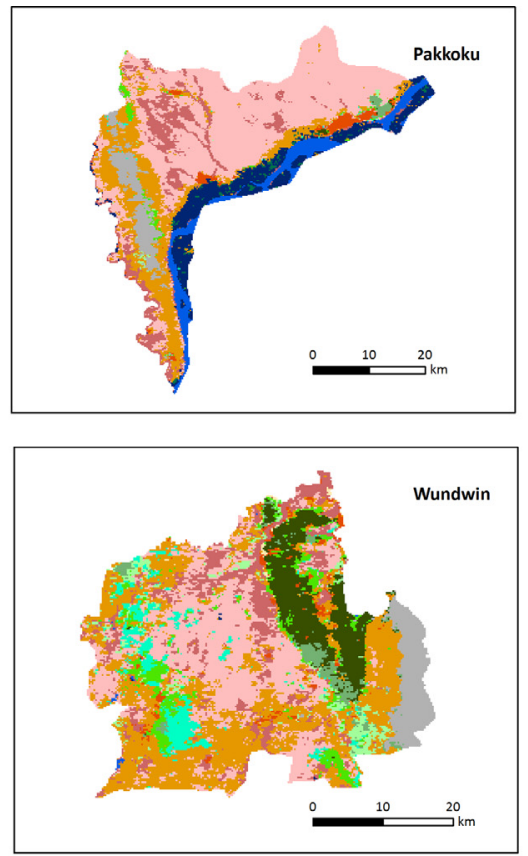

$\mathrm{m}$

Fig. 7. Map of cropping patterns and major non-agricultural land use/cover for the five Townships. The map was produced using 3-years of 8-day composite of MOD13Q1 product of MODIS Terra satellite, total of 3654 training and validation dataset, and applying the SVM classifier.
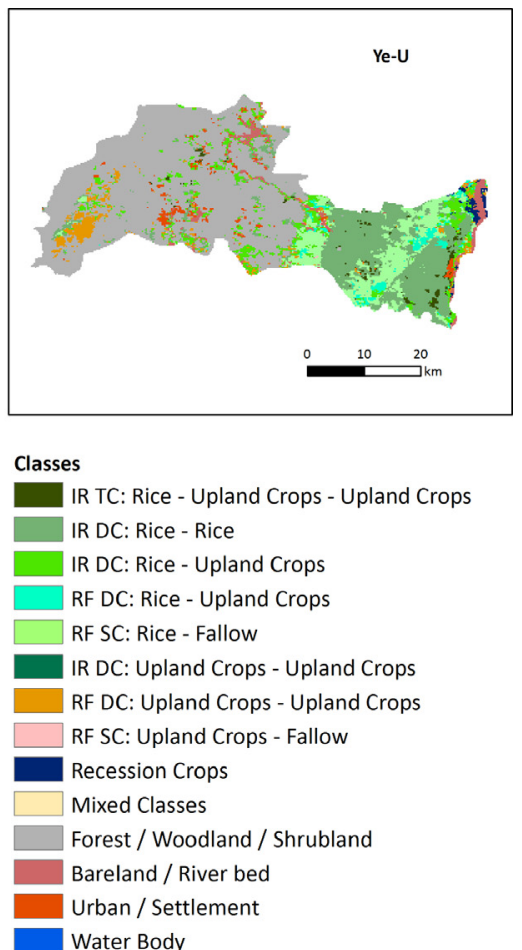
Table 2

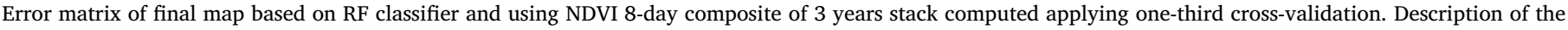

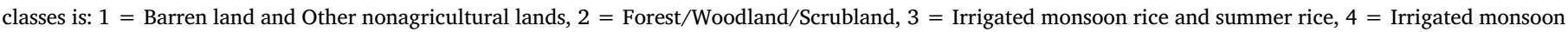

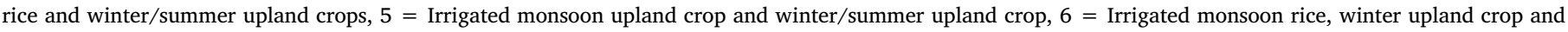

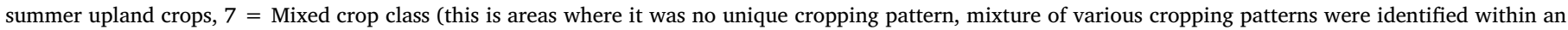

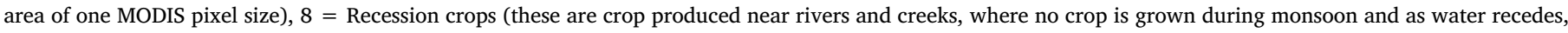

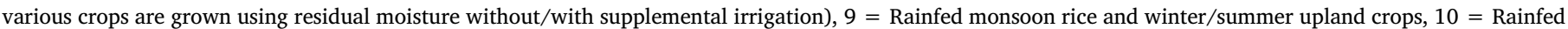

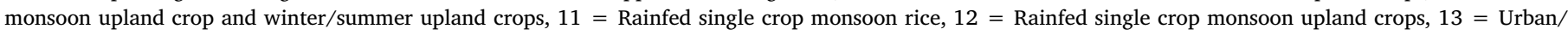
settlement areas, $14=$ Water.

\begin{tabular}{|c|c|c|c|c|c|c|c|c|c|c|c|c|c|c|c|c|c|}
\hline & & \multicolumn{14}{|c|}{ Reference data } & \multirow[b]{2}{*}{ Total } & \multirow[b]{2}{*}{ User } \\
\hline & & 1 & 2 & 3 & 4 & 5 & 6 & 7 & 8 & 9 & 10 & 11 & 12 & 13 & 14 & & \\
\hline \multirow[t]{17}{*}{ SVM predicted } & 1 & 136 & 0 & 0 & 2 & 0 & 0 & 0 & 2 & 0 & 0 & 0 & 2 & 1 & 1 & 144 & 94.4 \\
\hline & 2 & 0 & 128 & 1 & 0 & 0 & 0 & 0 & 0 & 0 & 0 & 0 & 0 & 0 & 0 & 129 & 99.2 \\
\hline & 3 & 0 & 0 & 71 & 2 & 0 & 1 & 0 & 0 & 1 & 0 & 3 & 0 & 0 & 0 & 78 & 91.0 \\
\hline & 4 & 0 & 1 & 1 & 67 & 0 & 3 & 0 & 0 & 4 & 1 & 1 & 1 & 1 & 0 & 80 & 83.8 \\
\hline & 5 & 0 & 0 & 0 & 1 & 36 & 0 & 0 & 1 & 0 & 1 & 0 & 0 & 0 & 0 & 39 & 92.3 \\
\hline & 6 & 0 & 0 & 2 & 1 & 0 & 48 & 0 & 0 & 0 & 0 & 0 & 0 & 0 & 0 & 52 & 92.3 \\
\hline & 7 & 0 & 0 & 0 & 0 & 0 & 0 & 39 & 0 & 0 & 0 & 0 & 0 & 0 & 0 & 39 & 100.0 \\
\hline & 8 & 0 & 0 & 0 & 0 & 1 & 0 & 0 & 111 & 0 & 1 & 0 & 0 & 0 & 1 & 115 & 96.5 \\
\hline & 9 & 0 & 0 & 1 & 4 & 0 & 0 & 0 & 0 & 36 & 0 & 0 & 1 & 0 & 0 & 43 & 83.7 \\
\hline & 10 & 0 & 1 & 1 & 1 & 0 & 0 & 0 & 0 & 4 & 112 & 6 & 5 & 1 & 0 & 132 & 84.8 \\
\hline & 11 & 1 & 0 & 3 & 0 & 0 & 0 & 0 & 0 & 1 & 1 & 56 & 1 & 0 & 0 & 63 & 88.9 \\
\hline & 12 & 2 & 0 & 0 & 0 & 0 & 0 & 0 & 0 & 2 & 6 & 1 & 54 & 0 & 0 & 64 & 84.4 \\
\hline & 13 & 0 & 0 & 0 & 1 & 1 & 0 & 0 & 0 & 0 & 1 & 0 & 0 & 66 & 0 & 69 & 95.7 \\
\hline & 14 & 0 & 0 & 0 & 0 & 0 & 0 & 0 & 0 & 0 & 0 & 0 & 0 & 0 & 172 & 172 & 100 \\
\hline & Total & 140 & 129 & 79 & 79 & 38 & 54 & 39 & 115 & 49 & 123 & 66 & 63 & 69 & 174 & 1217 & \\
\hline & Prod & 97.1 & 99.2 & 89.9 & 84.8 & 94.7 & 88.9 & 100.0 & 96.5 & 73.5 & 91.1 & 84.8 & 85.7 & 95.7 & 98.9 & & \\
\hline & Overall & & 93.0 & & & & & & & & & & & & & & \\
\hline
\end{tabular}

participatory mapping process and this resulted in a more complete enumeration of the cropping patterns (in the map legend) and a more accurate classification of the cropping patterns (in the map).

Ground-based data collection is expensive and time consuming, particularly when the area to be mapped is large and accessibility is constrained by factors such as absence of access roads and conflicts. Foody (2009) emphasizes the need for consideration of sample size and economic feasibility of sample collection. When resources being are limited, the sampling strategy needs to be economical and the quantity and quality of the data should allow for statistically meaningful analyses (Congalton, 1991). Recent study by Mialhe et al. (2015) has also highlighted the importance of participatory mapping approach in datapoor areas, and in areas such as conflict zones.

Our approach signifies the importance of examining the mapping accuracy in a participatory process particularly in conditions where sites are inaccessible or difficult to access. Arguably, the participation of the local community in the mapping process enables a more efficient way of sampling for to substantially improve map accuracy. The approach we applied has three advantages over more traditional approaches to field data collection for land cover mapping and specifically for crop pattern mapping in regions with complex and diverse cropping patterns. First, it minimized the time and resource needed for travelling and collection of reference data by facilitating an efficient and accurate way of generating data over large and inaccessible areas. Workshop participants provided detailed information on where our map classification was incorrect, providing insight on where further field visits were needed. Second, we were able to assess the location accuracy of mapping at locations for which we had no prior knowledge/reference data, which would not be possible through traditional accuracy assessment in remote sensing. Thirdly, the participants enumerated the different cropping practices in the five townships. This led to an improved and more complete listing of the cropping patterns and thus influenced the final map legend. This interactive and iterative process of mapping has resulted in substantial improvement of accuracy and completeness in terms of cropping pattern map legend.

While the importance of indigenous knowledge has long been well recognized in a wide range of subjects (Baul and McDonald, 2014; Rerkasem et al., 2009; Teffo, 2013), few studies have attempted to use local knowledge in improving the accuracy of mapping agricultural landscapes. Vergara-Asenjo et al. (2015) have, for the first time, demonstrated that local knowledge can improve land cover classification accuracies. In their study, Martínez-Verduzco et al. (2012) argue that community-based mapping is cost-effective compared to alternative approaches and can be applied in the rural zones of developing countries. Our findings are also in agreement with these previous studies. Further works on comparisons between participatory and conventional approaches would be useful to quantify the cost effectiveness and level of accuracies.

Coupled with participatory iterative mapping, our method involved the identification of suitable predictor data types and size.. Variation in accuracy in relation to the use of MODIS NDVI and EVI was an important finding. Consistently, NDVI was shown to result in higher accuracies than EVI. This result differs from the conclusions of a similar study by Wardlow and Egbert (2010), where NDVI and EVI performed equally well in mapping crops. An earlier study by Gill et al. (2006) which was designed to compare the relative suitability of MODIS NDVI and EVI in predicting vegetation foliage cover showed that NDVI predicted better than EVI. The fact that EVI is designed to suppress signals of non-vegetated surfaces, separability among surfaces with low vegetation cover (example, bareland and urban, as shown in Fig. 3, EVI profile) is low, hence leading to lower class accuracies for different nonagricultural classes.

The accuracy performance of the machine learning algorithms compared in this study increased with increasing size of predictor layers and training sample size, which is in agreement with studies such as Li et al. (2014). With a limited number of training samples, however, RF was shown to be more suitable than the other two classifiers. A number of studies have compared performances of various machine learning algorithms in mapping land cover types. However, the conclusions from many of such comparative studies are often inconsistent (FernándezDelgado et al., 2014; Li et al., 2014) depending on several factors including sizes and purity of training sample (Li et al., 2014; Shao and Lunetta, 2012), parameter tuning (Li et al., 2014; Sonobe et al., 2014), pixel-based and object-based classification (Duro et al., 2012; Qian et al., 2014; Sonobe et al., 2014), and performance criteria used in assessing the accuracy of the classifiers (Caruana and Niculescu-Mizil, 
2006). Studies by Adam et al. (2014) and Duro et al. (2012) indicated that machine learning algorithms such as SVM and RF performed similarly, and other studies such as that of Cracknell and Reading (2014), Fernández-Delgado et al. (2014) and Kampichler et al. (2010) showed $\mathrm{RF}$ to be the most accurate algorithm. Our results show that, with small sample size, the accuracy difference among the SVM, RF and C5.0 was larger as compared to bigger sample size. We did not observe any evidence of influence of the dataset being NDVI or EVI on accuracy difference among the three algorithms.

\section{Conclusion}

We evaluated influences of various aspects of mapping techniques and were able identify the suitability of different vegetation indices in mapping cropping patterns of highly fragmented agricultural landscape in Myanmar. An overall accuracy of 5\% was achieved when iterative participatory mapping was implemented, using RF algorithms and 8days NDVI composite layers for 3 years. While the three algorithms we compared didn't significantly vary with the type of VIs used, NDVI resulted in statistically higher accuracy compared to EVI. The participatory workshops where local expertise was brought into the map evaluation and map legend definition procedures has substantially improved the accuracies and completeness of the cropping pattern maps in an a region with complex agro-ecologies. The use of local knowledge was an essential source of information that was successfully incorporated within a conventional land cover mapping approach.

While an increase in the amount of training data has generally improved accuracy, the magnitude of accuracy improvement was different across different sample sizes and the accuracy improvement was non-linear. Compared to monthly and 16-day VI composites, 8-day composites resulted in higher accuracy. NDVI had higher accuracy than EVI. Even though the three machine learning algorithms (RF, SVM and C5.0) produced highly accurate maps, RF was relatively better when fewer training samples were used. As the number of training sample becomes larger and the size of predictor layers increases, all of the three algorithms performed well, though SVM was slightly better in most cases. In summary, these results provide insights into the importance of local knowledge for more complete enumeration of cropping patterns, efficient implementation of ground data collection and for producing more accurate land cover maps. We also highlight the need to identify the most appropriate classifier based on size of available training samples, and size and type of VI predictors. There is no single best classifier for all purposes. We recommend that to test a range of suitable classifiers for the case study at hand, based on well-defined criteria for what makes one classifier potentially more suitable than another for a given study. The classifier selection process should be transparent and robust with respect to current knowledge and use of state-of-the-art techniques.

\section{Funding}

This research was supported by the Livelihood and Food Security Trust Fund (LIFT) of the United Nations Office for Project Services (UNOPS) in Myanmar under a project titled: Reducing risks and improving livelihoods in the rice environments of Myanmar through better targeting of management options MOA Number R1.4/007/2012.

\section{CRediT authorship contribution statement}

Gudina Legese Feyisa: Conceptualization; Methodology; Formal analysis; Investigation; Writing - original draft; Writing - review \& editing. Leo Kris Palao: Data curation. Andy Nelson: Methodology; Validation; Supervision; Project administration; Writing - review \& editing. Murali Krishna Gumma: Investigation. Ambica Paliwal: Investigation. Khin Thawda Win: Investigation. Khin Htar Nge: Investigation. David E. Johnson: Funding acquisition; Writing - review
\& editing.

\section{Declaration of Competing Interest}

The authors declare that they have no known competing financial interests or personal relationships that could have appeared to influence the work reported in this paper.

\section{Acknowledgments}

The authors would like to acknowledge the support of the Ministry of Agriculture and Irrigation and the assistance of the farmers and the township staff of Monywa, Ye U, Pakoku, Wundwin and Pyawbwe.

\section{References}

Adam, E., Mutanga, O., Odindi, J., Abdel-Rahman, E.M., 2014. Land-use/cover classification in a heterogeneous coastal landscape using RapidEye imagery: evaluating the performance of random forest and support vector machines classifiers. Int. J. Remote Sens. 35, 3440-3458.

Araya, S., Lyle, G., Lewis, M., Ostendorf, B., 2016. Phenologic metrics derived from MODIS NDVI as indicators for plant available water-holding capacity. Ecol. Ind. 60, 1263-1272.

Atzberger, C., 2013. Advances in remote sensing of agriculture: context description, existing operational monitoring systems and major information needs. Remote Sensing 5, 949-981.

Baul, T.K., McDonald, M.A., 2014. Agro-biodiversity management: using indigenous knowledge to cope with climate change in the Middle-Hills of Nepal. Agric. Res. 3, 41-52.

Ben-Hur, A., Weston, J., 2010. A user's guide to support vector machines, data mining techniques for the life sciences. Springer 223-239.

Bivand, R., Keitt, T., Rowlingson, B., 2014. rgdal: Bindings for the Geospatial Data Abstraction Library. R package version 0.9-1, http://CRAN.R-project.org/package $=$ rgdal.

Boughton, D., Haggblade, S., Kham, L., Kongabaugh, S., Thaung, M., 2015. Overcoming Isolation: An Exploration of the Rapid Growth in Pulse Exports from Myanmar, 2015 Conference, August 9-14, 2015, Milan, Italy. International Association of Agricultural Economists.

Caruana, R., Niculescu-Mizil, A., 2006. An empirical comparison of supervised learning algorithms. In: Proceedings of the 23rd international conference on Machine learning, pp. 161-168.

Chen, C.-R., Chen, C.-F., Son, N.-T., 2014. Rice crop monitoring with multitemporal MODIS-Landsat data fusion, EGU General Assembly Conference Abstracts, p. 3540.

Chen, Y., Song, X., Wang, S., Huang, J., Mansaray, L.R., 2016. Impacts of spatial heterogeneity on crop area mapping in Canada using MODIS data. ISPRS J. Photogramm. Remote Sens. 119, 451-461.

Congalton, R.G., Green, K., 2008. Assessing the Accuracy of Remotely Sensed Data: Principles and Practices. CRC Press.

Cracknell, M.J., Reading, A.M., 2014. Geological mapping using remote sensing data: a comparison of five machine learning algorithms, their response to variations in the spatial distribution of training data and the use of explicit spatial information. Comput. Geosci. 63, 22-33.

Duro, D.C., Franklin, S.E., Dubé, M.G., 2012. A comparison of pixel-based and objectbased image analysis with selected machine learning algorithms for the classification of agricultural landscapes using SPOT-5 HRG imagery. Remote Sens. Environ. 118, $259-272$.

Duveiller, G., Defourny, P., 2010. A conceptual framework to define the spatial resolution requirements for agricultural monitoring using remote sensing. Remote Sens. Environ. 114, 2637-2650.

Eugster, M.J., Hothorn, T., Leisch, F., 2008. Exploratory and inferential analysis of benchmark experiments.

Exelis Visual Information Solutions, 2015. ENVI v. 5.2 Boulder, Colorado.

Fernández-Delgado, M., Cernadas, E., Barro, S., Amorim, D., 2014. Do we need hundreds of classifiers to solve real world classification problems? J. Machine Learn. Res. 15, 3133-3181.

Foerster, S., Kaden, K., Foerster, M., Itzerott, S., 2012. Crop type mapping using spectral-temporal profiles and phenological information. Comput. Electron. Agric. 89, $30-40$.

Foody, G.M., 2004. Thematic map comparison: evaluating the statistical significance of differences in classification accuracy. Photogramm. Eng. Remote Sens. 70, 627-633.

Foody, G.M., 2009. Classification accuracy comparison: hypothesis tests and the use of confidence intervals in evaluations of difference, equivalence and non-inferiority. Remote Sens. Environ. 113, 1658-1663.

Gill, T., Armston, J., Phinn, S., Pailthorpe, B., 2006. A comparison of MODIS time series decomposition methods for estimating evergreen foliage cover, 13th Australasian Remote Sensing and Photogrammetry Conference. Spatial Sciences Institute.

Gray, J., Friedl, M., Frolking, S., Ramankutty, N., Nelson, A., Krishna Gumma, M., 2014. Mapping Asian cropping intensity with MODIS. Selected Topics in Applied Earth Observations and Remote Sensing, IEEE Journal of 7, 3373-3379.

Gumma, M.K., Thenkabail, P.S., Hideto, F., Nelson, A., Dheeravath, V., Busia, D., Rala, A., 
2011. Mapping irrigated areas of Ghana using fusion of $30 \mathrm{~m}$ and $250 \mathrm{~m}$ resolution remote-sensing data. Remote Sensing 3, 816-835.

Gumma, M.K., Thenkabail, P.S., Maunahan, A., Islam, S., Nelson, A., 2014. Mapping seasonal rice cropland extent and area in the high cropping intensity environment of Bangladesh using MODIS 500m data for the year 2010. ISPRS J. Photogramm. Remote Sens. 91, 98-113.

Haggblade, S., Boughton, D., 2013. A Strategic Agricultural Sector and Food Security Diagnostic for Myanmar. Michigan State University, Department of Agricultural, Food, and Resource Economics.

Hijmans, R.J., 2015. raster: Geographic data analysis and modeling. R package version 2. 3-24. http://CRAN.R-project.org/package $=$ raster.

Hmimina, G., Dufrêne, E., Pontailler, J.-Y., Delpierre, N., Aubinet, M., Caquet, B., de Grandcourt, A., Burban, B., Flechard, C., Granier, A., 2013. Evaluation of the potential of MODIS satellite data to predict vegetation phenology in different biomes: an investigation using ground-based NDVI measurements. Remote Sens. Environ. 132, 145-158.

Hothorn, T., Leisch, F., Zeileis, A., Hornik, K., 2005. The design and analysis of benchmark experiments. J. Comput. Graphical Statistics 14, 675-699.

Kampichler, C., Wieland, R., Calmé, S., Weissenberger, H., Arriaga-Weiss, S., 2010. Classification in conservation biology: a comparison of five machine-learning methods. Ecol. Inf. 5, 441-450.

Kuhn, M., Wing, J., Weston, S., Williams, A., Keefer, C., Engelhardt, A., Cooper, T., Mayer, Z., Team, R.C., Benesty, M., Lescarbeau, R., Ziem, A., Scrucca, L., 2015. caret: Classification and regression training. http://CRAN.R-project.org/package $=$ caret. $\mathrm{R}$ package version 6.0-41 2

Lek, S., Guégan, J.-F., 2012. Artificial neuronal networks: Application to Ecology and Evolution. Springer Science \& Business Media.

Li, C., Wang, J., Wang, L., Hu, L., Gong, P., 2014. Comparison of classification algorithms and training sample sizes in urban land classification with Landsat thematic mapper imagery. Remote Sensing 6, 964-983.

Liu, M., Wang, M., Wang, J., Li, D., 2013. Comparison of random forest, support vector machine and back propagation neural network for electronic tongue data classification: Application to the recognition of orange beverage and Chinese vinegar. Sens. Actuators, B 177, 970-980.

Long, J.A., Lawrence, R.L., Greenwood, M.C., Marshall, L., Miller, P.R., 2013. Objectoriented crop classification using multitemporal ETM + SLC-off imagery and random forest. GIScience \& Remote Sensing 50, 418-436.

Maponya, M.G., van Niekerk, A., Mashimbye, Z.E., 2020. Pre-harvest classification of crop types using a Sentinel-2 time-series and machine learning. Comput. Electron. Agric. 169, 105164.

Martínez-Verduzco, G.C., Galeana-Pizaña, J.M., Cruz-Bello, G.M., 2012. Coupling community mapping and supervised classification to discriminate Shade coffee from Natural vegetation. Appl. Geogr. 34, 1-9.

Mialhe, F., Gunnell, Y., Ignacio, J.A.F., Delbart, N., Ogania, J.L., Henry, S., 2015. Monitoring land-use change by combining participatory land-use maps with standard remote sensing techniques: Showcase from a remote forest catchment on Mindanao, Philippines. Int. J. Appl. Earth Obs. Geoinf. 36, 69-82.

Michie, D., Spiegelhalter, D.J., Taylor, C.C., 1994. Machine learning, neural and statistical classification.

Pal, M., 2005. Random forest classifier for remote sensing classification. Int. J. Remote Sens. 26, 217-222.

Pal, M., Mather, P.M., 2005. Support vector machines for classification in remote sensing. Int. J. Remote Sens. 26, 1007-1011.

Peng, D.L., Huang, J.F., Li, C.J., Liu, L.Y., Huang, W.J., Wang, F.M., Yang, X.H., 2014. Modelling paddy rice yield using MODIS data. Agric. For. Meteorol. 184, 107-116.

Qian, Y., Zhou, W., Yan, J., Li, W., Han, L., 2014. Comparing machine learning classifiers for object-based land cover classification using very high resolution imagery. Remote Sensing 7, 153-168.
R Core Team, 2014. R: A Language and Environment for Statistical Computing. http:// www.R-project.org, Vienna, Austria.

Rajeswari, S., Suthendran, K., 2019. C5. 0: Advanced Decision Tree (ADT) classification model for agricultural data analysis on cloud. Comput. Electron. Agric. 156, 530-539.

Rerkasem, K., Yimyam, N., Rerkasem, B., 2009. Land use transformation in the mountainous mainland Southeast Asia region and the role of indigenous knowledge and skills in forest management. For. Ecol. Manage. 257, 2035-2043.

Rodriguez-Galiano, V., Ghimire, B., Rogan, J., Chica-Olmo, M., Rigol-Sanchez, J., 2012. An assessment of the effectiveness of a random forest classifier for land-cover classification. ISPRS J. Photogramm. Remote Sens. 67, 93-104.

Sakamoto, T., Gitelson, A.A., Arkebauer, T.J., 2014. Near real-time prediction of US corn yields based on time-series MODIS data. Remote Sens. Environ. 147, 219-231.

Sarkar, D., 2008. Lattice: Multivariate Data Visualization with R. http://lmdvr.r-forge.rproject.org.

SeinnSeinn, M., Ahmad, M., Thapa, G., Shrestha, R., 2015. Farmers' adaptation to rainfall variability and salinity through agronomic practices in lower Ayeyarwady Delta, Myanmar. J. Earth Sci. Climatic Change 6, 1.

Seo, B., Lee, J., Lee, K.-D., Hong, S., Kang, S., 2019. Improving remotely-sensed crop monitoring by NDVI-based crop phenology estimators for corn and soybeans in Iowa and Illinois, USA. Field Crops Res. 238, 113-128.

Shao, Y., Lunetta, R.S., 2012. Comparison of support vector machine, neural network, and CART algorithms for the land-cover classification using limited training data points. ISPRS J. Photogramm. Remote Sens. 70, 78-87.

Siebert, S., Portmann, F.T., Döll, P., 2010. Global patterns of cropland use intensity Remote Sensing 2, 1625-1643.

Sonobe, R., Tani, H., Wang, X., Kobayashi, N., Shimamura, H., 2014. Parameter tuning in the support vector machine and random forest and their performances in cross-and same-year crop classification using TerraSAR-X. Int. J. Remote Sens. 35, 7898-7909.

Tatsumi, K., Yamashiki, Y., Torres, M.A.C., Taipe, C.L.R., 2015. Crop classification of upland fields using Random forest of time-series Landsat 7 ETM + data. Comput. Electron. Agric. 115, 171-179.

Teffo, L., 2013. Rural communities as sites of knowledge: a case for African epistemologies. Indilinga: African Journal of Indigenous Knowledge Systems 12, 188-202.

Tun, T., Kennedy, A., Nischan, U., 2015. Promoting agricultural growth in Myanmar: a review of policies and an assessment of knowledge gaps.

Vergara-Asenjo, G., Sharma, D., Potvin, C., 2015. Engaging stakeholders: assessing accuracy of participatory mapping of land cover in Panama. Conserv. Lett. 8, 432-439.

Waldner, F., Chen, Y., Lawes, R., Hochman, Z., 2019. Needle in a haystack: mapping rare and infrequent crops using satellite imagery and data balancing methods. Remote Sens. Environ. 233, 111375.

Waldner, F., Defourny, P., 2017. Where can pixel counting area estimates meet userdefined accuracy requirements? Int. J. Appl. Earth Obs. Geoinf. 60, 1-10.

Wardlow, B.D., Egbert, S.L., 2010. A comparison of MODIS 250-m EVI and NDVI data for crop mapping: a case study for southwest Kansas. Int. J. Remote Sens. 31, 805-830.

Wardlow, B.D., Egbert, S.L., Kastens, J.H., 2007. Analysis of time-series MODIS $250 \mathrm{~m}$ vegetation index data for crop classification in the US Central Great Plains. Remote Sens. Environ. 108, 290-310.

Wickham, H., 2009. ggplot2: elegant graphics for data analysis. http://had.co.nz/ ggplot2/book.

Yee, M.S., Nawata, E., 2014. Land Use and Farming Systems in Dry Zone, Myanmar: A Case Study in Kani, Sagaing Region. Tropical Agriculture and Development 58, 169-179.

Zhong, L., 2012. Efficient crop type mapping based on remote sensing in the Central Valley, California.

Zhu, Z., Gallant, A.L., Woodcock, C.E., Pengra, B., Olofsson, P., Loveland, T.R., Jin, S. Dahal, D., Yang, L., Auch, R.F., 2016. Optimizing selection of training and auxiliary data for operational land cover classification for the LCMAP initiative. ISPRS J. Photogramm. Remote Sens. 122, 206-221. 